\title{
Violencia, conflicto e integración social en el agro uruguayo
}

DIEGO E. PIÑEIRO*

\section{Introducción}

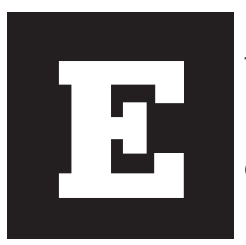
I año pasado ${ }^{1}$ integrantes del MST (Movimiento de los Sin Tierra de Brasil) tomaron un fundo a $50 \mathrm{~km}$ de la frontera uruguaya. Este acontecimiento tuvo una amplia repercusión en la prensa uruguaya. Un equipo periodístico de la TV brasileña me entrevistó y sorprendidos, me pedían que explicase cúales eran las razones por las cuales en Uruguay no existía un movimiento de los que no tienen tierra y porqué no existían posibilidades de que ocurriese algo que era tan frecuente en Brasil como la ocupación de tierras.

Sin duda que este tema es hoy mas importante que hace algunos años, como consecuencia del proceso de integración regional que está ocurriendo en el Cono Sur. Hay quienes se preguntan si este proceso de ocupación de tierras no se propagará a los socios de Brasil que hasta ahora estaban relativamente exentos de estos episodios. ¿No nos contagiaremos? Es la pregunta de muchos uruguayos propietarios de tierras en la frontera.

Las asimetrías entre los cuatro países socios del Mercosur son muchas pero una significativa, es la cuestión de la violencia rural. Si tuviésemos que ordenar de mayor a menor grado de violencia en el campo,

\footnotetext{
*Ingeniero Agrónomo con Maestría en Sociología Rural de la Universidad de Wisconsin y Profesor Titular de Sociología Rural de las Facultades de Ciencias Sociales y de Agronomia de la Universidad de la Republica.

1 Este articulo fue presentado originalmente en el Seminario Internacional Violencia y Cidadanía organizado (entre otros) por el Instituto de Filosofia e Ciências Humanas, Departamento e Programa de Pós-Graduação em Sociologia da Universidade Federal do Rio Grande do Sul, en junio de 1998.
} 
posiblemente este orden fuese Brasil, Paraguay, Argentina, Uruguay. Pero no cabe duda que la distancias en este orden no son las mismas entre los distintos países.

Lo que importa y sorprende en este Brasil de fin de siglo es la violencia física de origen político en el medio rural, ligado a las reivindicaciones por la tierra, a condiciones dignas de vida y de trabajo y al reconocimiento al derecho a organizarse. Por el contrario es preciso reconocer que este tipo de violencia está prácticamente ausente en el Uruguay de hoy. Por lo tanto una de las tareas necesarias es explicar esta diferencia.

Esto no significa la inexistencia de otras formas de violencia en nuestra sociedad rural, particularmente la que Tavares dos Santos (1992) llamase "violência costumeira" (violencia cotidiana) que es aquella inserta en las relaciones sociales de trabajo y que es una expresión de las relaciones de dominación entre clases y grupos sociales o de las relaciones de dominación de género, etnia o categoría social.

\section{Una mirada a nuestra historia rural}

Hubo un tiempo en que en la sociedad rural uruguaya predominaban las relaciones de violencia política. Para ello es necesario remontarse más de un siglo atrás. En la última mitad del siglo XIX la industrialización europea y el incremento de la demanda de alimentos para las clases trabajadoras europeas provocaron el alza de los precios de la carne y de la lana. El Uruguay podía ser un fuerte productor y exportador de estos productos, pero para ello era necesario introducir los cambios técnicos (la mestización del ganado, el alambramiento) que permitiesen aumentar los saldos exportables y adaptarse a los gustos de la demanda. Para ello era necesario afianzar la propiedad rural. Entre 1840 y 1890 el alambramiento de los campos y la delimitación de la propiedad, provoca la expulsión de la población pobre: pequeños propietarios sin títulos de propiedad y gauchos (población rural que eran sólo parcialmente trabajadores), que algunos his- 
toriadores han estimado en más del 10\% de la población rural de la época (Barrán y Nahum, 1967). A esto se superponen las guerras civiles que son tanto luchas entre facciones políticas como luchas sociales, en la medida que las tropas de uno y otro bando estaban formadas, en muchos casos, por estos desplazados por el ordenamiento de la propiedad. Pero la alianza entre una burguesía comercial (portuaria) y una burguesía agraria se impuso definitivamente. Los límites de las propiedades se fijaron definitivamente, se sanearon los títulos de propiedad, se repartió la escasa tierra pública que aún quedaba. Así, la frontera agrícola que en muchos países de América Latina se cierra recién a mediados de este siglo y en algunos países aún está abierta (y Brasil y Paraguay son ejemplo de ello por las extensas superficies de tierras públicas que aún hoy quedan) en Uruguay se cierra a fines del siglo XIX. Repartida la tierra, la población excedentaria se asienta en los ejidos de los pueblos mientras el gaucho domesticado se transforma en el peón asalariado rural².

En 1904 suena el último disparo de las guerras civiles. Derrotados los ejércitos blancos, el triunfante Partido Colorado inicia un período de construcción del Estado y la nacionalidad que marcarán el resto del siglo. El Censo de 1908 detecta la existencia de un total de 44 mil explotaciones rurales de las cuales la mitad son pequeñas explotaciones. A partir de allí el crecimiento de la explotación familiar es incesante por los próximos 50 años. En 1956 se llega al máximo con 66 mil explotaciones familiares. Es decir que, a través de procesos de colonización pública y privada y a través de la simple compra y subdivisión de parcelas, muchas de las familias desplazadas por los procesos de cercamiento (y sus descendientes) encontraron ubicación en el campo como pequeños productores ganaderos y agrícolas. Pero por otro lado una temprana industrialización y urbanización

2 José Pedro Barrán muestra como este pasaje de una sensibilidad "bárbara" a una sensibilidad "civilizada" se produjo en las últimas décadas del siglo XIX. La sensibilidad del Novecientos disciplinó la sociedad: impuso la gravedad y el "empaque " al cuerpo. En realidad esta fue la época de la vergüenza, la culpa, la disciplina. Barrán, José Pedro. Historia de la Sensibilidad en el Uruguay. Tomo 2. El disciplinamiento (1860-1920). Facultad de Humanidades y Ciencias, Editorial Banda Oriental, 1990. 
hace que importantes contingentes de emigrantes campo-ciudad encuentren lugar en las tareas urbanas.

El desarrollo industrial y urbano ocurrido en la primera mitad del siglo XX produjo un mercado interno para la agricultura familiar que aseguró su expansión, pero además el Estado la protegió con precios sostén, créditos, asistencia técnica gratuita, e infraestructura, lo cual le dio seguridades y márgenes de rentabilidad (Piñeiro, 1985).

Los trabajadores asalariados rurales no tuvieron igual suerte. La legislación protectora del trabajo rural fue tardía (1940) y además inaplicable. Los salarios rurales fueron muy bajos (CLAEH-CINAM, 1962), no cumpliéndose ni siquiera los mínimos establecidos por la ley, predominando la precariedad del contrato, la inestabilidad y la arbitrariedad patronal. Sin embargo las condiciones iniciales (excedentariedad de fuerza de trabajo) y la extensividad de la estancia ganadera y por lo tanto la dispersión física de los trabajadores atentaron contra cualquier posibilidad de organización o de rebelión. El clientelismo político y la cooptación patronal fueron los instrumentos de dominación de las clases propietarias. Las primeras organizaciones sindicales de trabajadores asalariados rurales aparecerán recién en 1940 y sufrirán mucha persecución (González Sierra, 1994).

En la década del 60 se desmorona el modelo del país batllista, de crecimiento hacia adentro, signado por la industrialización que substituye importaciones y por un Estado de Bienestar. En el sector agropecuario las dificultades provienen del fuerte deterioro de los precios de la lana y otros productos al finalizar el período de alza ocasionado por la demanda generada por la II Guerra Mundial y la Guerra de Corea. La traslación de excedentes del sector agropecuario a otros sectores, en particular a la industria y a la burocracia estatal provoca tensiones internas.

En la sociedad rural dos acontecimientos marcan la existencia de situaciones de descontento que confluirán en acciones públicas reivindicativas. Por un lado el Movimiento Ruralista (década del 50), agrupamiento de los agricultores y ganaderos familiares medios, los más 
castigados por la crisis de precios del sector, que se nuclean convocados por un locutor radial y luego dirigente político, Benito Nardone, en un movimiento de protesta en defensa de los precios de sus productos y contra la extracción de ingresos por parte del Estado. Lo más significativo de este movimiento es que su alianza con y finalmente cooptación por parte del Partido Nacional posibilita su acceso al poder (vía elecciones) y la rotación entre Partidos por primera vez en la historia (Methol Ferre, Cosse, Abulafia).

Por otro lado, en la década del 60, las marchas de los trabajadores de la caña de azúcar y del arroz hacia la capital inauguran una forma de lucha inédita y la aparición de un actor social hasta entonces amordazado. Estas marcarán el punto más alto de la organización del proletariado rural. Se crean varios sindicatos y agremiaciones que reúnen a los trabajadores rurales según el rubro en que trabajan. Reclaman mejores salarios y condiciones de trabajo, la posibilidad de organizarse, la eliminación de "listas negras" ,etc. Algunos partidos políticos de izquierda tendrán fuerte presencia entre sus dirigentes. En la década siguiente los sindicatos serán duramente perseguidos y finalmente disueltos por directivas del gobierno "de-facto".

Durante la dictadura militar (1973-1984) se pone en marcha un modelo económico de crecimiento hacia afuera. Precedido de los planes de ajuste y estabilización, la apertura económica y la producción competitiva exportable es la nueva racionalidad. Esto significará profundos cambios en el agro. Sobre un trasfondo en el que la estancia ganadera y las exportaciones de carne y lana siguen siendo lo más importante, se estimulan (por parte del Estado) el desarrollo de rubros exportables: leche, cebada cervecera, citrus, arroz, forestación, etc. La Integración Regional (Mercosur) dinamiza la producción agroindustrial. Los indicadores de la década del 90 son positivos en materia de crecimiento y productividad del sector agropecuario. Hay reinversión, crece la agroindustria, mejora la eficiencia productiva (Irigoyen, 1996). 
Sin embargo los indicadores sociales no son positivos y muestran el costo social que ha tenido este crecimiento. Una profunda descomposición de la agricultura familiar, el descenso del empleo, niveles de pobreza que rondan el $40 \%$ de la población trabajadora rural y en consecuencia la continua emigración de población rural. Sobre estos aspectos nos extenderemos en las páginas siguientes.

\section{Conflicto rural}

¿Cuáles son en la actualidad las formas de violencia en nuestra sociedad rural? Creo que por más que busquemos no será posible encontrar formas de violencia política. A diferencia de la situación en Brasil o en Paraguay (y aún de la Argentina) no hay episodios de violencia política rural. Esto a pesar de que hay muchas situaciones originadas en condiciones de dominación social en las que los sectores más desfavorecidos de la sociedad rural deben soportar condiciones de "violencia cotidiana".

Para fines de una mayor claridad de exposición es posible referirse a los productores familiares por un lado y por otro a los trabajadores asalariados rurales.

Los productores familiares

La apertura económica desprotegió nuestros mercados internos. Los productores familiares, tradicionales abastecedores de este mercado se vieron forzados a competir con producción que ingresaba de otros países (incluso a veces con subsidios en sus lugares de origen). La transmisión de los precios de productos e insumos en nuestros mercados produjo situaciones en que los productores familiares no pudieron competir. Problemas de escala, de acceso a tecnología adecuada, de la forma subordinada como se integraron a los Complejos Agro-Industriales provocó la inviabilidad económica de muchos de ellos. 
Los censos muestran un acelerado proceso de descomposición de la agricultura familiar: si había 65.000 establecimientos con menos de 100 hectáreas en 1965, el último censo (1990) registró solo 35.000 establecimientos con esa superficie. Es decir que en 30 años se perdió la mitad de los establecimientos. La tierra perdida por este sector social fue a parar a manos de los establecimientos más grandes (de más de 1.000 hectáreas). Ha habido un fuerte y notorio proceso de concentración de la propiedad de la tierra y de expulsión de productores familiares, lo cual ha constituido una de las formas de violencia socia/mas notoria en el medio rural (Piñeiro, 1990).

Por otro lado, pero vinculado al punto anterior, es preciso destacar que el modelo de agricultura impulsado está más próximo al de la Revolución Verde y más lejos de un modelo de agricultura sustentable. Esto consolida una forma de hacer agricultura poco respetuosa de los ciclos biológicos y de los recursos naturales. Uruguay tiene problemas de erosión y de pérdida de fertilidad de los suelos que han sido más graves en las tierras de los pequeños productores, quienes esquilmaron sus tierras para sacarle los beneficios que no provenían del tamaño o de la adecuación tecnológica (Victora, 1993). Nuevamente la concentración de las tierras y demás medios de producción en pocas manos ha impedido un desarrollo armónico con los recursos naturales. Hay una violencia ambiental cuyos orígenes, profundidad y consecuencias recién ahora se están percibiendo.

\section{Los asalariados rurales}

El proceso de expansión del capitalismo agrario en las últimas tres décadas así como perjudicó a los productores familiares, expandió el trabajo asalariado rural. Si ya el salario rural es una violencia en sí mismo (por sus bajos niveles), en años recientes evolucionó desfavorablemente en relación con los salarios urbanos.

Por otro lado, los nuevos rubros exportables emplean una tecnología que al acortar los periodos de cosecha y al mecanizar la mayoría de las labores incide incrementando el trabajo zafral y el empleo precario. En 
forma más reciente, en el período comprendido entre los dos últimos censos de población (1985-1996), el trabajo asalariado rural ha descendido bruscamente, como consecuencia de los cambios técnicos ocurridos en la agricultura. Bajos salarios, zafralidad, precariedad y menos empleo inciden en que las mediciones sobre pobreza rural (1992) hayan detectado cifras abrumadoras de familias por debajo del nivel de pobreza: $42 \%$, cuando en las áreas urbanas para la misma fecha estaba en el entorno del 12\% (FIDAMGAP, 1992).

Una consecuencia poco conocida de la violencia ejercida en los procesos laborales son los accidentes de trabajo. Según los registros del Banco de Seguros del Estado el sector rural tiene el índice de accidentes laborales más alto, mayor aún que el de la construcción y los servicios. Se registran 6.000 accidentes al año, casi el 20\% del total en el sector agropecuario. Ello incluye 12 muertes anuales durante el trabajo y como consecuencia del mismo (BSE, 1995, p. 95). "Las actividades realizadas a caballo, el manejo de vacunos y el manejo de materiales pesados como troncos, rolos, postes, tablas son fuente de la mayor parte de los accidentes". La invisibilidad de este problema es un ejemplo de como el Estado uruguayo amortiguó los conflictos con el sencillo recurso de ignorarlos.

Una de las formas de violencia más extendida contra los trabajadores rurales es ejercida por la estancia ganadera y consiste en la política de contratar sólo al trabajador expulsando a la familia del establecimiento. Esta práctica (centenaria) fue y es posible por el temprano cierre de la frontera agrícola y por la disposición excedentaria de la mano de obra que permitió que la estancia ganadera "eligiese" a los que dijeran ser solteros. Mientras la estancia no debió pagar por el costo de reproducción de su fuerza de trabajo, ésta se reprodujo en la miseria de los rancheríos o "pueblos de ratas". La separación del trabajador rural de su familia, forzada, ha sido una de las peores violencias impuesta por el modo de producción ganadero extensivo (CLAEH-CINAM, 1962). 
Finalmente, es preciso referirse a las dificultades que los trabajadores asalariados han experimentado para organizarse. Ya se mencionó que recién en la década del 40 se fundan los primeros sindicatos, pero no es realmente hasta la década del 60 que estos cobran cierta presencia en el escenario político. Sin embargo, esta organización estuvo restringida a los trabajadores de ciertos cultivos (del azúcar, del arroz, de los tambos, entre otros) pero nunca se logró una organización de los trabajadores de la ganadería que son la amplia mayoría. Esto se explica, como se dijo antes, por la cerrada oposición patronal que se ha opuesto vehementemente no sólo a la formación de organizaciones laborales sino a cualquier tipo de acción que implique el reconocimiento de su posible existencia como grupo social diferenciado y con derechos propios ${ }^{3}$.

\section{La integración social}

A pesar de las formas de violencia cotidiana difusa que hemos reseñado, no hay, en la actualidad, manifestaciones de violencia política. ¿Cómo se explica?

En la sociedad uruguaya hay mecanismos de integración social y de amortiguación de los conflictos, extendidos a la sociedad rural, que nos ayudan a entender esta situación. Por un lado el Estado uruguayo ejerce el monopolio de la fuerza y lo hace sin dudas y con legitimidad. No existe la posibilidad de que otros ejerzan la fuerza con aceptación social (como puede ser el caso de los hacendados en Brasil que tienen sus propios grupos armados para defender la propiedad y aún de las organizaciones como la UDR que apoyan más o menos desembozadamente la violencia patronal organizada con el argumento de la defensa de la propiedad amenazada y la inoperancia de la fuerza pública).

3 Un ejemplo muy reciente fue el conflicto que se suscitó en torno a la posibilidad de que existiesen Comisiones Paritarias para el Agro, entre el Ministro de Trabajo y Seguridad Social Lic. Hugo Fernández Faingold y la Federación Rural del Uruguay en 1987. Ante una invitación del Ministro para que concurriesen ambas partes a una reunión para constituir una Comisión Paritaria, las organizaciones patronales se negaron a concurrir y montaron una fuerte ofensiva periodística en contra de la iniciativa, acusando al ministro de profesar ideas marxistas. La iniciativa fue rápidamente abandonada. Los salarios rurales se siguen (hasta hoy) fijando administrativamente por parte del Estado (el Ministerio de Trabajo) y el salario real sigue disminuyendo. 
Por otro lado, también es cierto que el derecho a la propiedad de los medios de producción (y los otros derechos que de él se derivan, a disponer de ellos, a usarlos o no, etc.) no está en cuestión. La sociedad uruguaya es profundamente propietarista y sería impensable que alguien (impunemente o con cierta legitimidad social) atentase contra los derechos de propiedad establecidos a fines del siglo pasado sobre la tierra rural.

Entre los mecanismos de integración más extendidos y eficaces está la escuela pública. El tamaño pequeño del país, los escasos accidentes geográficos y una política deliberada del Estado han derivado en que la cobertura haya sido muy completa, Ilegando a los rincones más apartados del país. Casi no hay analfabetismo con lo que esto significa como factor de integración social. En la actualidad, incluso ocurre el fenómeno inverso: que la emigración de población rural está dejando algunas escuelas rurales con escasos alumnos.

El clientelismo político y la inclusión en el aparato estatal como trabajador público ha sido otro factor de integración. El ejército, la policía, las intendencias han sido eficazmente empleadas como instrumentos de proporcionar empleo, pagando votos a la par que descomprimiendo el desempleo rural.

Los planes de vivienda subsidiada instrumentados desde MEVIR, un organismo público no estatal, también cumplen un importante papel de integración social. La mayoría de las 12.500 viviendas que ha construido esta institución en el medio rural lo fueron en los últimos 15 años. En ellas han encontrado protección principalmente familias de trabajadores rurales y de pequeños productores que no encontraron lugar en el campo y por ello se trasladaron a los pequeños poblados en los que MEVIR construye sus programas de vivienda. Estos programas cubren aproximadamente a un 1520 \% de las familias rurales. Según la situación económica del comprador se subsidia hasta la mitad del valor de la vivienda.

Una serie de Programas de Desarrollo Rural provenientes de la órbita estatal han amortiguado los efectos negativos del programa de apertura 
económica y de integración regional. El Programa de Apoyo a la Pequeña Producción (PRONAPPA con préstamos del FIDA), el Programa de Desarrollo de la Granja, el Programa Nacional de Desarrollo del Riego y otros programas de menor envergadura, han distribuido entre los pequeños productores, crédito agrícola con ciertos niveles de subsidio y asistencia técnica y capacitación, generalmente en forma gratuita, con el objetivo de facilitar los procesos de adecuación tecnológica y de reconversión productiva que son precisos para poder competir en los mercados internacionales.

Por último, la electrificación rural (que cubre una importante proporción del territorio), la caminería y la telefonía rural, en un país pequeño de distancias cortas (tanto geográficas como sociales) han facilitado la adopción creciente de pautas de vida urbanas y la integración social de la mayoría de los habitantes de la campaña.

Sin embargo, también es claro que en Uruguay existen situaciones de potencial conflicto rural. Por un lado hay una demanda por tierras para trabajar, provenientes de los agricultores jóvenes y de los productores familiares exitosos que aspiran a ampliar sus establecimientos. Esta demanda es canalizada a través del Instituto Nacional de Colonización aunque la tarea colonizadora está prácticamente detenida en años recientes por la falta de apoyo gubernamental para destinarle recursos con los cuales pueda comprar tierra para su posterior reparto.

Hay conflictos que tienen que ver con las políticas agrícolas: con el Estado por las tasas de interés de los créditos, por los impuestos rurales, por demandas crediticias, etc. Con las agroindustrias por los precios de los productos, por las condiciones de comercialización, etc. Los productores familiares arguyen que a través de estos mecanismos se les extraen excedentes económicos que atentan contra su reproducción como grupo social. Sin embargo, estos conflictos son canalizados a través de las principales organizaciones de productores familiares: la Comisión Nacional de Fomento Rural, la Intergremial de Productores de Leche, la Asociación de Colonos, etc. Existen espacios de participación para estas organizaciones en 
Comisiones Gubernamentales, en Instituciones Públicas (INIA, Plan Agropecuario, INAVI, etc.) a través de las cuales canalizan sus demandas.

Entre los trabajadores rurales, la realidad es distinta. Luego de un intenso proceso de organización sindical a la salida de la dictadura (19851990), en que llegó a haber 12 sindicatos y una Federación Nacional de Trabajadores Rurales, varios de ellos desaparecieron, no habiendo hoy más de media docena activos, en los rubros agroindustriales (citrus, hortícolas, frutícolas, forestales) pero con poco peso real. Objetivamente es preciso reconocer que los asalariados rurales no tienen canales de expresión ni de participación. Es un grupo social bloqueado como clase, por la imposibilidad de constituirse en actor social. A ello contribuye, como se dijo, desde la eficaz oposición patronal a cualquier forma de organización, a los mecanismos de clientelismo y cooptación implicados en el empleo estatal o la vivienda subsidiada, pasando por las propias dificultades impuestas por la dispersión y el aislamiento de los trabajadores.

En resumen y para concluir, en el medio rural las propias relaciones sociales de producción y los mecanismos de dominación ejercen una violencia difusa sobre los trabajadores asalariados rurales y sobre los productores familiares. Esto solo podría justificar la existencia de una violencia política o de clase. Sin embargo también hay mecanismos de integración social fuertes que desalientan esas respuestas (la escuela rural, el clientelismo político y patronal, los planes de desarrollo rural, la vivienda subsidiada, la progresiva urbanización de la fuerza de trabajo rural) y organizaciones sociales que son capaces de canalizar orgánicamente el disenso. Esto es lo que explica que, habiendo situaciones de violencia difusa ejercida sobre trabajadores y pequeños productores rurales y, aun habiendo situaciones de extracción de excedentes hacia el Estado o hacia el sistema financiero y comercial que generan situaciones de conflicto rural, éstas no hayan derivado en procesos en los cuales los dominados responden con violencia política o de clase. 
Sociologias, Porto Alegre, ano 4, no 8, jul/dez 2002, p. 206-219

Referencias

BANCO DE SEGUROS DEL ESTADO. Almanaque del Banco de Seguros del Estado, 1995.

COSSE, Gustavo. Acerca de la democracia, el sistema político y la movilización social: el caso del "ruralismo" en Uruguay. In: Estudios Rurales Latinoamericanos. V. 5, n. 1, 1982, p. 77-100.

BARRÁN, Jose P. y NAHUM, Benjamin. Historia Rural del Uruguay Moderno (1851-1885). V. 1. Montevideo: Ediciones de la Banda Oriental, 1967.

CINAM-CLAEH. Situación económica y social del Uruguay rural. Montevideo: Centro Latinoamericano de Economía Humana, s/f.

GONZALEZ SIERRA, Yamandú. Los olvidados de la tierra: vida, organización y luchas de los sindicatos rurales. Montevideo, Uruguay: Nordan Comunidad, 1994.

FIDA/MGAP/EQUIPOS CONSULTORES. Perfil y caracterización de la pobreza rural. Montevideo: 1992.

IRIGOYEN, Rodolfo. In: El País agropecuario. Año1, n. 12, Febrero de 1996.

PIÑEIRO, Diego. Formas de resistencia de la agricultura familiar. Montevideo: Ediciones Banda Oriental/CIESU, 1985.

PIÑEIRO, Diego. La agricultura familiar: el fin de una época. In: Diego E. Piñeiro (Editor). Nuevos y no tanto: los actores sociales para la modernización del agro uruguayo. Montevideo: Editorial Banda Oriental/CIESU, 1991.

TAVARES DOS SANTOS, José Vicente. Violência no campo: o dilaceramento da cidadania. In: Reforma Agraria, v. 22, n. 1, Jan/abr, 1992, p. 4-11.

VÏCTORA, Carlos. Erosión de suelos, medio ambiente, y agricultura sostenible en el Uruguay. In: Alternativas para un desarrollo agrario sostenible. Montevideo: Fundación Prudencio Vazquez y Veja, 1993, p. 31-41. 


\section{Resumen}

En el Uruguay no ha habido en las últimas décadas episodios de violencia física en el campo derivados de la violencia de clase o de la violencia política. Los pequeños productores y los trabajadores rurales están sometidos a situaciones de violencia cotidiana: disminución de la rentabilidad de sus pequeñas explotaciones, expulsión de sus tierras y emigración para los primeros. Bajos salarios, accidentes laborales, e impedimentos para organizarse para los segundos. Sin embargo, los mecanismos de integración social con que cuenta la sociedad uruguaya amortiguan los disensos e impiden que estos desemboquen en formas de violencia.

Palabras-clave: violencia, conflicto, integración social, Uruguay rural. 